\title{
THERMAL PERFORMANCE OF FLAT PLATE HEAT SINK WITH ATTACHED HEAT SHIELD*
}

\author{
Mohamed R. Shaalan, Mohamed A. Saleh, \\ Osama M. Mesalhy, Mohamed L. Elsayed** \\ Mechanical Power Eng. Dept., Zagazig University, Egypt.
}

\begin{abstract}
A parametric study has been carried out to study the effect of design parameters on a new-design feature of using a heat shield on performance of parallel plate fin heat sink. Both numerical and experimental approaches are performed. These parameters include Reynolds number, number of fins, fin height, and shield inclination angle. The attachment of a shield to a heat sink enhances its thermal performance and thermal resistance decreases with increasing Reynolds number, but this effect diminishes at high Reynolds numbers. So, enhancement of thermal performance by a shield is much greater and effective at low Reynolds numbers. Also, variation of shield inclination angle causes complicated variation of the flow field in the space near the heat sink. It is found that the angle of inclination that yields minimum thermal resistance for the case of the lowest fin height, $(\mathrm{H}=15 \mathrm{~mm})$ ranges from $90-120^{\circ}$, while for higher heat sink height, the optimum angle ranges between $120-135^{\circ}$.
\end{abstract}

KEY WORDS: Heat sink, shield, plate fin, electronic cooling, CFD.

\section{PERFORMANCE THERMIQUE DE LAVABO PLAQUE DE CHALEUR PLAT AVEC ÉCRAN THERMIQUE JOINTS}

\section{RÉSUMÉ}

Une étude paramétrique a été réalisée pour étudier l'effet des paramètres de conception sur une nouvelle fonctionnalité de conception de l'utilisation d'un bouclier thermique sur le rendement des puits de chaleur à plaques parallèles aileron. Les deux approches numériques et expérimentales sont réalisées. Ces paramètres incluent le nombre de Reynolds, le nombre d'ailerons, hauteur d'ailette, et l'angle d'inclinaison de bouclier. L'attachement d'un bouclier à un dissipateur thermique améliore ses performances thermiques et diminue la résistance thermique avec l'augmentation du nombre de Reynolds, mais cet effet diminue au nombre de Reynolds élevé. Ainsi, l'amélioration des performances thermiques par un bouclier est beaucoup plus grande et efficace à faibles nombres de Reynolds. En outre, la variation de l'angle d'inclinaison bouclier provoque une variation compliquée du champ d'écoulement dans l'espace près de l'évier de la chaleur. Il est constaté que l'angle d'inclinaison qui donne une résistance thermique minimale pour le cas de la hauteur la plus basse aileron, ( $\mathrm{H}=15 \mathrm{~mm}$ ) varie de 90-120o, tandis que pour la hauteur de la chaleur élevée évier, les plages de l'angle optimal entre $120-135^{\circ}$.

MOTS CLÉS: radiateur, bouclier, aileron plaque, refroidissement de l'électronique, la CFD.

\footnotetext{
* Received: 24/8/2011, accepted: 14/9/2011 (Original Paper)

** Contact author(mec_moh86@yahoo.com, 01142882416)
} 


\section{Thermal Performance of Flat Plate Heat Sink With Attached Heat Shield}

Shaalan, Saleh, Mesalhy, Elsayed

\section{INTRODUCTION}

Over the past decade, the heat flux in electronic packages has increased drastically due to the reduction in package size combined with higher power dissipation. The efficiency of electronic products suffers from the lack of an adequate heat dissipation mechanism, possibly causing damage as the temperature rises. Therefore, effective thermal management of electronic products is of priority concern. Forced air-cooling is a popular electronic cooling approach. It is adopted widely because simplicity, economical, safe, and high reliability.

Recently, several studies on heat sink design for improved cooling of electronic component and its performance have been conducted. Morega et al. [1] investigated the minimization of the thermal resistance between a stack of parallel plates and a free stream. The best heat transfer was obtained when the plates were uniformly spaced; there existed an optimal number of plates that minimized the thermal resistance for a specified free stream and overall dimensions of the stack.

The effect of flow bypass on the performance of longitudinal fin arrays has been reported by several workers. Sparrow et al. [2] and Sparrow and Kadle [3] investigated the effect of tip clearance on thermal performance of longitudinal plate fin heat sink. It is reported that the ratio of heat transfer coefficient with and without clearance, to be strongly affected by the tip clearance to fin height ratio, and independent of air flow rate and fin height. Writz et al. [4] studied the effects of flow bypass on the performance of ducted longitudinal heat sinks. It is reported that the value of flow bypass was found up to $60 \%$ and resulted in a reduction of the overall heat transfer rate. An optimal design of fin arrays for a given flow conditions and shroud configuration was also reported. Azar and Tavassoli [5] studied the effect of heat sink dimensions and fin density on its thermal performance. It is reported that the selection of heat sink depends not only on its thermal resistance, but also on the number of fins it has and how it is coupled to the board. Simons [6] estimated the air flow that actually passes through the fin passages of a ducted heat sink in the presence of flow bypass and also investigated the effect of this flow bypass on its thermal performance. It is reported that the flow bypass has a substantial effect on thermal performance of heat sink, and this effect can significantly increase its thermal resistance specially, with high fin density.

Elshafei [7] assessed the thermal fluid performance of a plate-fin heat sink under cross flow conditions, both experimentally and theoretically for different stream velocity and fin density. The data showed that the pressure drop increases with increasing Reynolds number and fin height but decreases with increasing inter-fin space and fin width. Jonsson and Palm [8] studied experimentally the thermal performance of plate-fin heat sink; they assessed the effects of fin height and bypass conditions on the thermal performance of various heat sinks. The thermal resistance has been found to increase with increasing height and width of the wind tunnel duct.

Thermal characteristics of plate fin heat sink under forced air cooling were experimentally and numerically investigated using CFD code by Adam and Izundu [9]. It is reported that much of the augmentation in the heat transfer rates from heat sink is related to the increased surface area. Yuan [10] used CFD software FLUENT to study the bypass effect of the cross flow in the fin-to-fin passage of a platefin heat sink. The results showed that the air flow enters the fin-to-fin passage and decelerates with distance downstream, thus influencing the effect of heat transfer. Prstic and Bar-Cohen [11] compared between the thermal performances of a heat sink if it is fully shrouded, partially shrouded, or if a shield is used in the case of partially shrouded. The heat shield is placed in front of a plate-fin heat sink. It was found that the use of a thin sheet metal heat shield can decrease the bypass effect and induce additional fluid to enter the fin-to-fin channel of a plate-fin heat sink. The thermal performance of this heat shield configuration is near that of a fully shrouded configuration, but its pressure drop is markedly decreased. Li et al. [12] investigated numerically the performance of a plate-fin heat sink undergoing cross-flow forced convection with the shield. They concluded that the shield that tends to decrease the bypass flow effect has a great influence on the 
variation of the thermal-fluid field and enhancing the performance of the heat sink.

The review shows that the performance of the heat sink in a cross flow is influenced markedly by the flow velocity and the geometries of the heat sink. So, this work aims at investigating experimentally and numerically the effectiveness of using a heat shield to decrease the bypass effect and effect on thermal performance of a plate-fin heat sink. Moreover, the effects of changing the Reynolds number, fin number, fin height, and inclination angle of a shield on thermal performance have been investigated.

\section{EXPERIMENTAL INVESTIGATION}

\subsection{Experimental Setup}

A schematic drawing of the experimental setup used is shown in Fig. (1). The test rig is composed basically from a wind tunnel operated in suction mode as indicated by the arrows so it's called open-looped suction-type. A calibration of the empty tunnel to check flow uniformity and the measurements of the velocity heads over the full width of the tunnel show that the flow is uniform over almost $90 \%$ of the channel cross section. A Plexiglas test section of same cross section as the tunnel is mounted in the middle of the wind tunnel where the heat sink and the shield are mounted. To show how the total test rig is operated, consider the inlet of the main duct as a starting point, the flow first passes through the inlet of the main duct and encountered a bell mouth. At the end, the flow is driven to the Laboratory room. Air flow is drawn into the wind tunnel through a honeycomb. The honeycomb is used to straighten the flow inside the test section, to prevent the transmission of a swirl motion of the air stream from the fan back into the working section. The entry length for the tunnel is of enough length to assure a uniform flow upstream of the test section. The inlet velocities range from $1 \mathrm{~m} / \mathrm{s}$ up to $20 \mathrm{~m} / \mathrm{s}$.

\subsection{Test Section Components and Configuration}

This is the main part of the experimental test facility. The general layout of the test section that contained a plate-fin array is shown in Fig. (2) The test section walls are made of acrylic or Plexiglas $(\mathrm{k}=0.2 \mathrm{~W} / \mathrm{m} \cdot \mathrm{K})$ plates of a thickness of $5 \mathrm{~mm}$ to ease observation of the tested models during the experiments. The side walls and floor are fixed and the ceiling is movable. The test section is assembled to prevent air from leakage into the test section. The test section has the same dimensions as the main duct inlet (125 mm x $125 \mathrm{~mm}$ ) with a total length of $1000 \mathrm{~mm}$. It is installed directly at the exit of the main duct of the wind tunnel. An opening with dimensions (140 mm x 140 $\mathrm{mm}$ ) at distance $570 \mathrm{~mm}$ from the starting point of the test section is created in the bottom surface where the heater assembly is fixed. A shield is attached at the heat sink tip and fixed in the top wall. The shield is formed from an acrylic plate with a width of $100 \mathrm{~mm}$ and a thickness of $2 \mathrm{~mm}$. The inlet temperature of the air stream was taken as the average reading of four thermocouples located at 45 $\mathrm{mm}$ from the entrance of the test section.

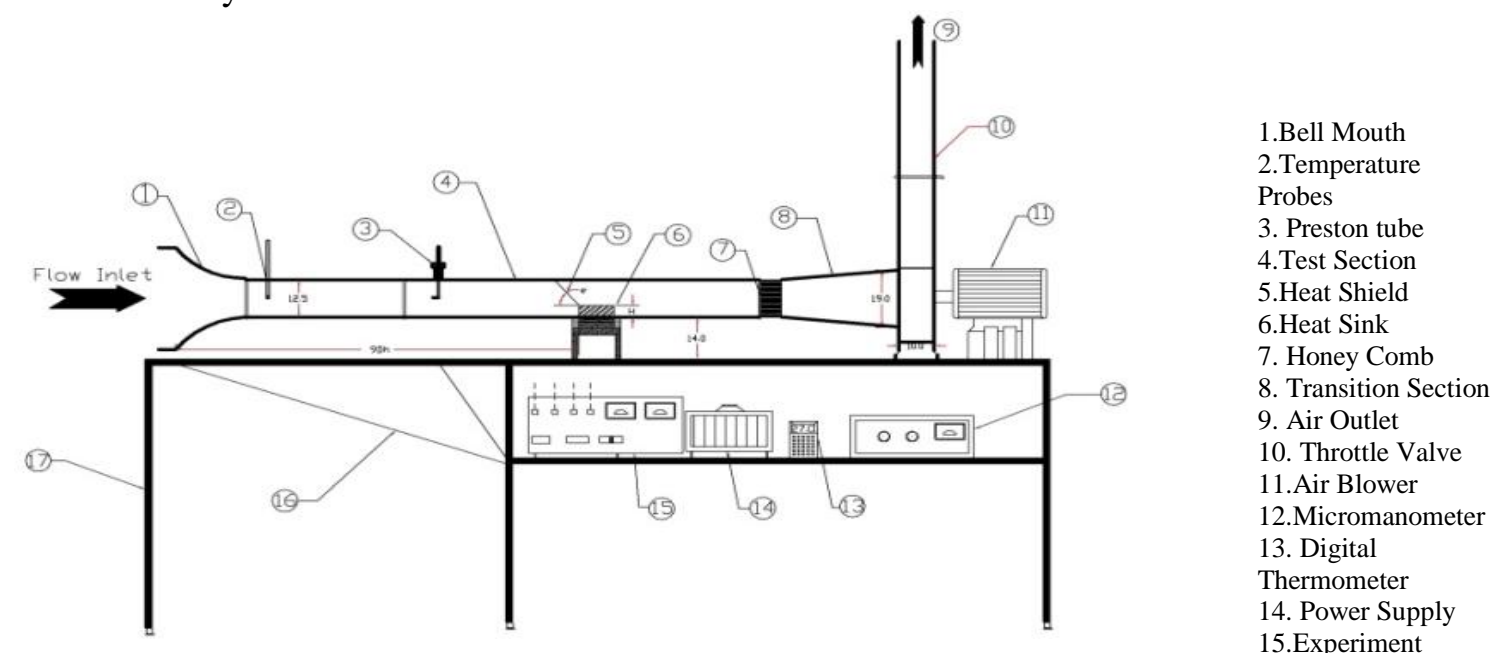

Fig.1: Wind tunnel configuration 


\section{Thermal Performance of Flat Plate Heat Sink With Attached Heat Shield}

Shaalan, Saleh, Mesalhy, Elsayed

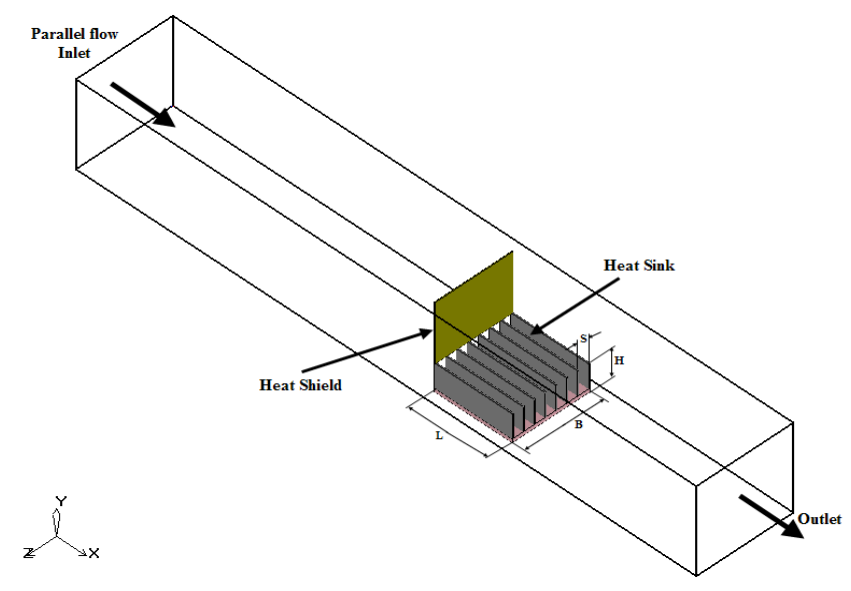

Fig.2 Test section (flat plate heat sink with a heat shield)

\subsection{Heater Block Assembly}

The Heater block is made of a block of copper, thermal conductivity $(\mathrm{k}=400 \mathrm{~W} / \mathrm{m} \cdot \mathrm{K})$. It has the same length and width as the heat sink (10 $\mathrm{cm})$ so the spreading resistance effects can be neglected Seaho [13].The thickness of the heater block is $1 \mathrm{~cm}$. Two $80 \mathrm{~W}$ pencil heaters are fitted into the heater block as shown in Fig. (3). A glass wool of thermal conductivity $0.023 \mathrm{~W} / \mathrm{m} . \mathrm{K}$ is placed at the bottom and sides of the heater plate to minimize heat losses. The heat losses are estimated from measuring the temperature across the insulation substrate. The total power is calculated by measuring the voltage drop and the current through the heaters. It was found that the maximum value of heat losses from the sides and the bottom of the heater plate was about $5 \%$ of the total power. Also it was found that all heat dissipated by the pencil heaters was nearly uniformly distributed through the heater block. This has been proven by noticing the uniformity of the heater surface temperature during its operation in natural convection environment.

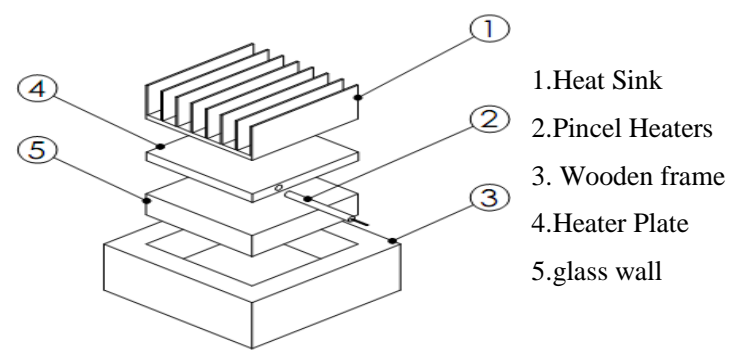

Fig. 3: Complete heater assembly

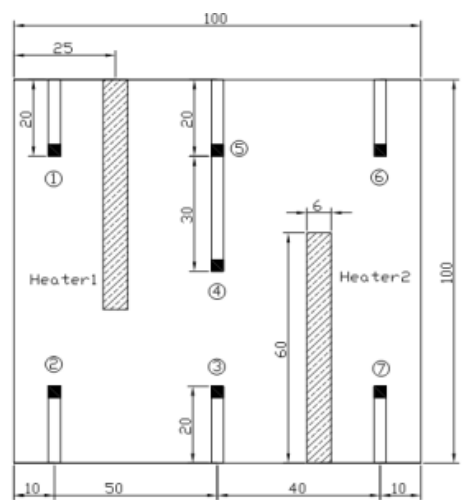

Fig. 4: Locations of thermocouples at bottom of heater plate.

The electrical power input to the heater was controlled by a variac transformer to obtain constant heat flux along the base plate. Also, the heater block and the glass-wool have been assembled in wooden frame fabricated from Beech Wood as shown in Fig. (3).To measure the temperatures at the Heater block base seven T-Type (copper-constantan) thermocouples are mounted through $3 \mathrm{~mm}$ deep holes to the bottom of the Heater block as shown in Fig. (4).

\subsection{Heat Sinks (tested models)}

The configurations and detailed dimensions of the heat sink models are given in Table (1), and illustrated in Fig. (5). The models are fabricated from aluminum alloy 2017, which has a thermal conductivity of $(k=202$ $\mathrm{W} / \mathrm{m} \cdot \mathrm{K}$ ) using $\mathrm{CNC}$ Milling. 


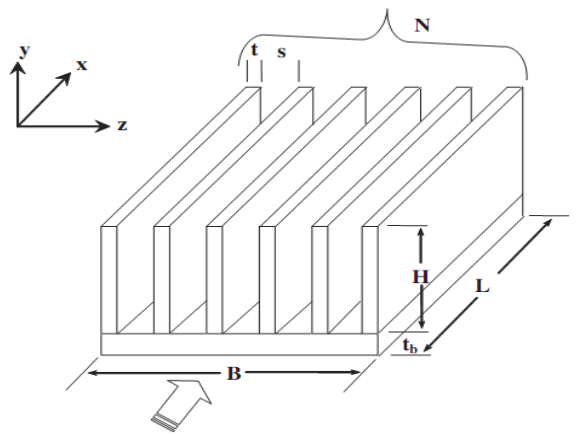

Fig.5: Geometry of heat sink

Table 1: Date of tested models

\begin{tabular}{|l|l|l|l|l|l|l|l|}
\hline Dim. & H.S.\#1 & $\mathbf{\# 2}$ & $\mathbf{\# 3}$ & $\mathbf{\# 4}$ & $\mathbf{\# 5}$ & $\mathbf{\# 6}$ & $\mathbf{\# 7}$ \\
\hline $\mathbf{L}(\mathbf{m m}$ & 100 & 100 & 100 & 100 & 100 & 100 & 100 \\
\hline $\mathbf{B}(\mathbf{m m})$ & 100 & 100 & 100 & 100 & 100 & 100 & 100 \\
\hline $\mathbf{t}_{\mathbf{b}}(\mathbf{m m})$ & 5 & 5 & 5 & 5 & 5 & 5 & 5 \\
\hline $\mathbf{t}(\mathbf{m m})$ & 1.5 & 1.5 & 1.5 & 1.5 & 1.5 & 1.5 & 1.5 \\
\hline $\mathbf{S}(\mathbf{m m})$ & 12.57 & 7.45 & 5.0 & 12.5 & 7.45 & 5.0 & 12. \\
\hline $\mathbf{H}(\mathbf{m m}$ & 15 & 15 & 15 & 35 & 35 & 35 & 55 \\
\hline $\boldsymbol{N}_{\boldsymbol{f}}$ & 8 & 12 & 16 & 8 & 12 & 16 & 8 \\
\hline
\end{tabular}

Experiments were conducted to validate the computational model. Tests were conducted for seven heat sink geometries for parallel flow. Heat sink pressure drop and thermal resistance data were taken for different flow rate conditions and different heat shield inclination angle $(\theta)$. For each heat sink, experimental measurements were carried out at four different velocities by adjusting the throttle gate $\left(\mathrm{V}_{\mathrm{d}}=1,3,5\right.$, and $\left.7 \mathrm{~m} / \mathrm{s}\right)$, and at eight different heat shield position, $(\theta=30,45$, $60,90,120,135$, and $\left.150^{\circ}\right)$. The heat sinks are mounted at the bottom of the wind tunnel duct in such a way that the fin base is flush with the duct wall and plate fin with its base are protrude, also it was firmly bolted to the heater plates with a thin layer of thermal grease of conductivity $(\mathrm{k}=0.7 \mathrm{~W} / \mathrm{m} \cdot \mathrm{K})$. The base plate temperature was measured using three $\mathrm{T}$ thermocouples at the bottom of heat sink base plate. Arithmetic average represents a value for the mean base plate temperature, $\mathrm{T}_{\mathrm{b}}$.

\subsection{Data Reduction}

The present experimental study is divided into two parts: fluid flow and heat transfer studies. The essential quantities determined in the study of fluid flow are as the followings:

Duct velocity can be calculated from the measured data by the standard Pitot tube through the following relationship:

$$
\mathrm{V}_{\mathrm{d}}=\sqrt{2 g\left(\rho_{w} / \rho_{w}\right) \Delta h_{p}}(\mathrm{~m} / \mathrm{s})
$$

Where, $\Delta \mathrm{h}_{\mathrm{p}}$ is the head difference between the total and static pressure heads through Pitot tube, $\mathrm{m} \mathrm{H}_{2} \mathrm{O}, \quad \rho_{a}, \rho_{w}$ are the air and water density respectively, $\mathrm{kg} / \mathrm{m}^{3}$.

In evaluating the thermal performance of the heat sink, the thermal resistance is defined as:

$$
\mathrm{R}_{\mathrm{th}}=\frac{T_{b}-T_{a}}{Q}=\frac{\Delta T}{Q}(K / w)
$$

Where, $\mathrm{T}_{b}$ is the mean base plate temperature. $\mathrm{T}_{\infty}$ is the temperature of the cooling air.

The convection heat transfer rate can be expressed by Newton's Law of Cooling:

$h=\frac{Q}{T_{b}-T_{a}} \times \frac{1}{A_{t}}=\frac{1}{R_{t h} A_{t}}\left(W / m^{2} \cdot K\right)$

Where, the heat transfer area $A_{t}$ is given by:

$A_{t}=2 N L H+(N-1) s L$

The Reynolds number is given by:

$$
\operatorname{Re}_{D h}=\frac{\rho_{a i r} V_{d} D_{D h}}{\mu}
$$

Where, $D_{\text {hd }}$ is the hydraulic diameter of the section, and $\mu$ is the dynamic viscosity of air.

The Nusselt number is a measure of heat transfer when convection takes place is calculated using:

$$
N u_{D h}=\frac{h D_{h}}{K_{f}}
$$

Where, $\mathrm{k}_{f}$ is air thermal conductivity W/m.K.

The relative uncertainty in the duct velocity is given by:

$$
\frac{w_{V d}}{V_{d}}=\left[\left(-0.5 \frac{w_{\rho_{\text {air }}}}{\rho_{\text {air }}}\right)^{2}+\left(0.5 \frac{w_{P_{1}}}{P_{1}}\right)^{2}\right]^{\frac{1}{2}}
$$

Where $\frac{w_{\rho_{a i r}}}{\rho_{\text {air }}}$ and $\frac{w_{P_{1}}}{P_{1}}$ are the uncertainties in air density and heat sink inlet pressure, respectively. The experimental uncertainties in $\Delta \mathrm{P}, \mathrm{R}_{\mathrm{th}}$ (or $\mathrm{h}$ or $\mathrm{Nu}$ ) were the result of uncertainties in the experimental measurement of temperature, pressure, flow rate, voltage, current and uncertainty in the thermal and fluid properties of the cooling fluid. The result of that analysis is summarized in Table (2). 


\section{Thermal Performance of Flat Plate Heat Sink With Attached Heat Shield}

Shaalan, Saleh, Mesalhy, Elsayed

Table 2: Uncertainties in compound variables

\begin{tabular}{|l|l|}
\hline Compound Variable & Uncertainty $( \pm \%$ ) \\
\hline Duct Velocity, m/s & 1.7 \\
\hline Pressure drop , pa & 0.382 \\
\hline Reynolds Number & 1.9 \\
\hline Thermal Resistance, & 2.01 \\
\hline Convective heat transfer & 2.01 \\
\hline Nusselt Number & 2.01 \\
\hline
\end{tabular}

\section{NUMERICAL INVESTIGATION}

\subsection{Problem Description}

The geometry of the theoretical model and the boundary conditions are illustrated in Figs. (6) Because of symmetry, the computations are carried out only on the half of the volume (3000 $\mathrm{mm} \times 125 \mathrm{~mm} \times 62.5 \mathrm{~mm})$ to save computation time. The thermal and flow fields were calculated numerically with commercial CFD software FLUENT 6.3.26, according to the following assumptions: the flow is steady state; the flow is incompressible and turbulent; the fluid and the solid properties are constant, and the effects of gravitation and thermal radiation are neglected. The equations governing the fluid are the Reynolds-averaged Navier-Stokes equations and the energy equation and based on the aforementioned assumptions these equations can be expressed as:

$$
\begin{aligned}
& \frac{\partial}{\partial x_{i}}\left(\rho v_{i}\right)=0.0 \\
& \frac{\partial}{\partial x_{j}}\left(\rho V_{i} V_{j}\right)=-\frac{\partial p}{\partial x_{i}}+\frac{\partial \tau_{i j}}{\partial x_{j}} \\
& \frac{\partial}{\partial x_{i}}\left[V_{i}(\rho E+p)\right]=\frac{\partial}{\partial x_{i}}\left(K \frac{\partial T}{\partial x_{i}}\right)
\end{aligned}
$$

where, $i$ : is a tensor indicating 1,2 , and 3 and

$\tau_{i j}$ is the viscous stress tensor.

We utilized RNG $\kappa-\varepsilon$ turbulent model to solve the complicated turbulent thermal flow field with Enhanced Wall Function approach in the near-wall regions to fit the wall boundary conditions, Fluent [14]. The solid regions, fins and the heat sink base, are also considered, where only heat diffusion equation is solved.

The solution was considered converged when the scaled residual of the energy equation reaches $10^{-7}$ and the scaled residuals of other equations reach $10^{-4}$.

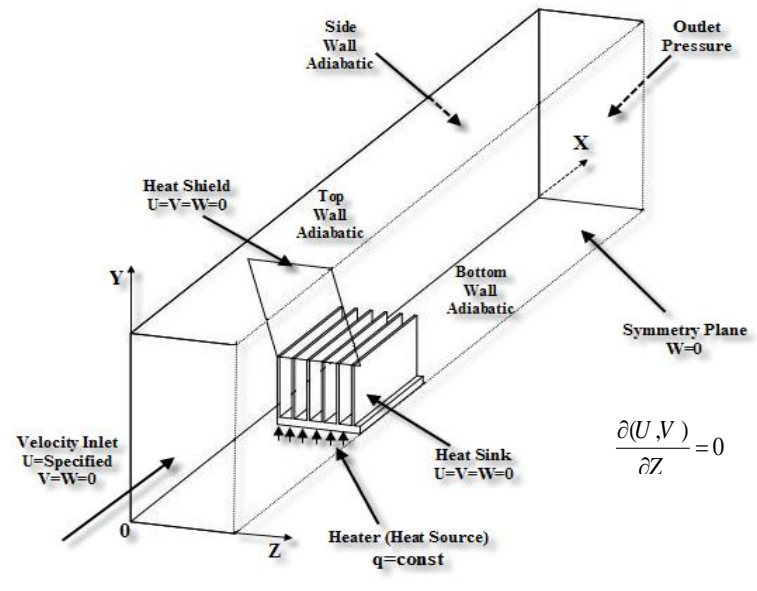

Fig.6: Boundary conditions for heat sink with shield

\subsection{Mesh Generation And Discretization}

The geometry and mesh of the computational model that described in the previous section were generated separately using GAMBIT 2.4.6. Hex/Sub Mapped and Hex/wedge Cooper meshing scheme was used in the present study with refining the mesh near walls and beside sharp edges.

Fig. (7) Shows the configuration of the computational domain mesh for both the cases of a heat sink without shield and with shield of inclination angle $\theta=45^{\circ}$, respectively. To test the dependence of the numerical results on the grid density, calculations were carried out with different mesh densities in the $\mathrm{X}, \mathrm{Y}$ and $\mathrm{Z}$ directions. As recommended by Fluent [14], the first grid points adjacent to the walls were kept at $\mathrm{y}^{+}$values between 1 and 5. The applied grid system was certified under conditions of a heat sink with $\mathrm{N}=16$ fins and $\mathrm{H}=40 \mathrm{~mm}$, and at $\mathrm{Re}=23600$. The grid sensitivity analysis was analyzed mainly to obtain grid independent temperature distributions. The computational results of the mean surface temperature of the heat sink varied to give about $2 \%$ deviation in thermal resistance when the number of grids increased from 128,340 to 624,960 . When the grid size increased from 476,160 to 624,960 only $0.02 \%$ variation in thermal resistance is obtained as shown in Fig. (8). It is clear that the effect of grid size on the computed result diminishes for grids of 476,160 nodes. 

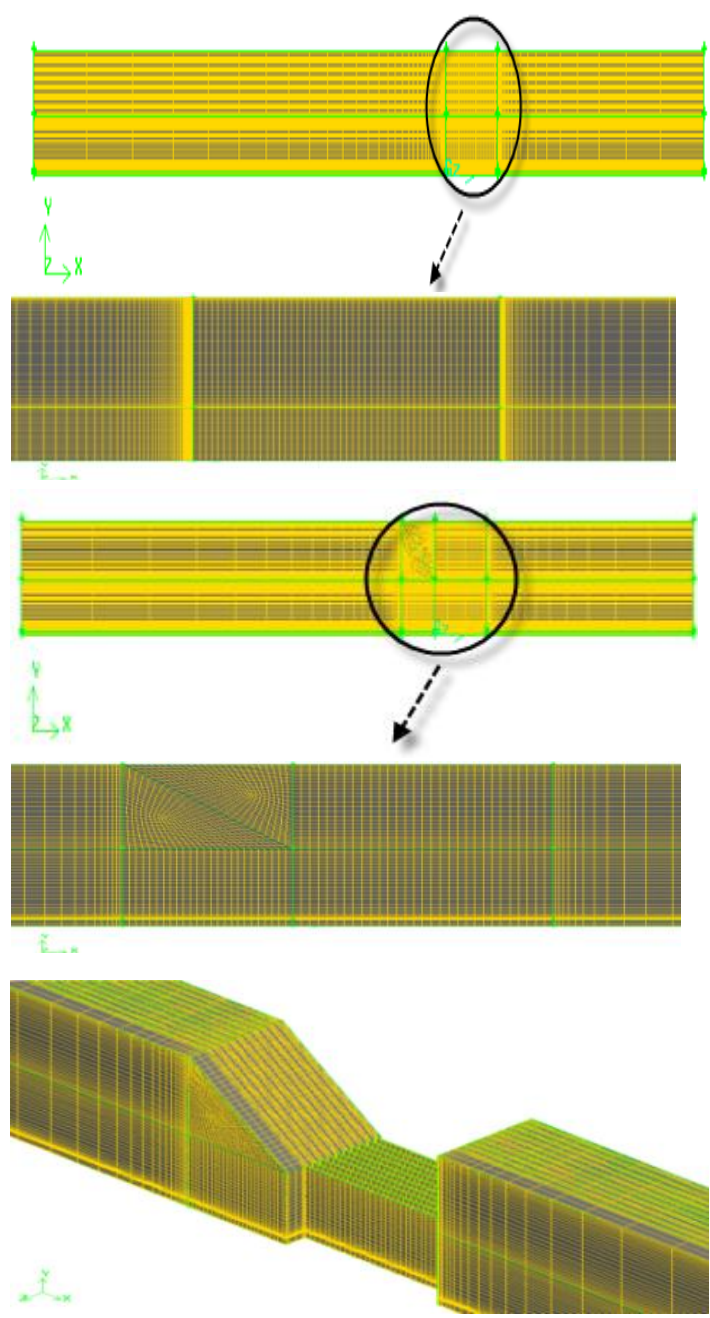

Fig.7: Computation domain configuration of heat sink with shield $\left(\theta=45^{\circ}\right)$

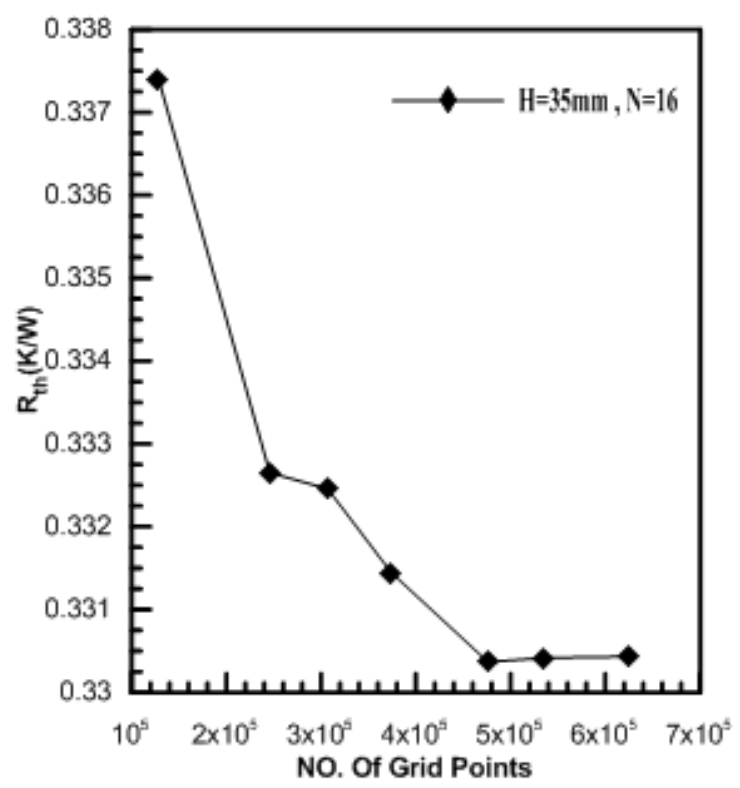

Fig.8: Grid dependence test

\subsection{Validation}

For the model of plate-fin heat sink with heat shield of the present study, there is no related experimental investigation. To validate the computations, numerical results for $3 \mathrm{D}$ platefin heat sink without a shield are compared with the experimental measurements of Jonsson and palm [8]. They performed several experiments on plate-fin heat sink, which is similar to the array of plate fins in the present study. For validation, the array of plate fins like the heat sink in their experiment is modeled for the same fluid and thermal conditions, and the results are compared. Comparison between present numerical results and experimental measurements is illustrated in Fig. (9). This Figure shows a good agreement between the present numerical results and experimental measurements. Therefore with valid numerical modeling, computations will be conducted for heat sink with a shield.

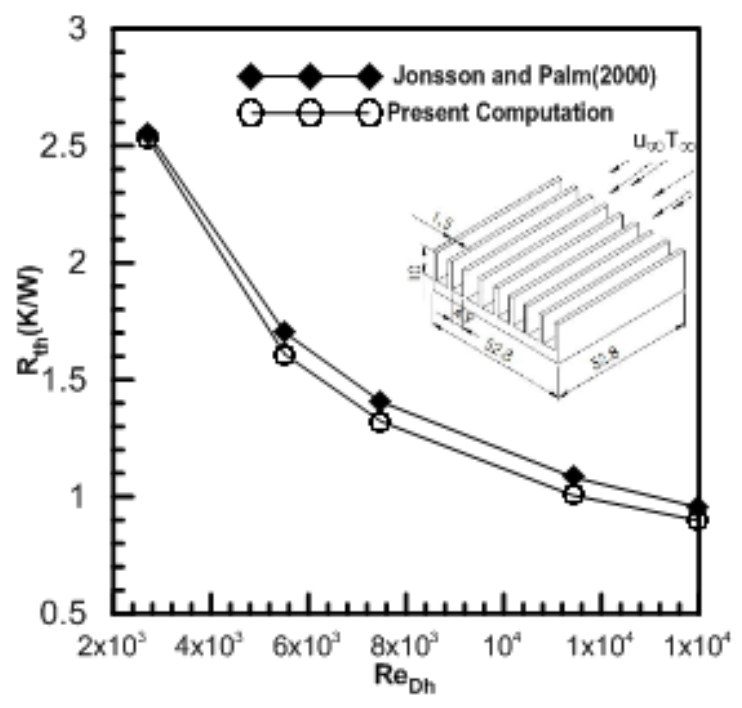

Fig.9: Comparison with Experimental results by Palm and Jonsson [8]

\section{RESULTS AND DISCUSSION}

\subsection{Shield Effect on Velocity and Temperature Fields}

Inserting heat shield in the bypass region is expected to make a drastic change in velocity and temperature fields around the heat sink. So, to get insight understanding of its effect on thermal performance, the flow and temperature fields will be illustrated first for a selected design of a heat sink design shown in 


\section{Thermal Performance of Flat Plate Heat Sink With Attached Heat Shield}

Shaalan, Saleh, Mesalhy, Elsayed

Table (3). Some indicators are used to evaluate the performance of the heat sink. These Indicators are; The Pressure Drop across a heat sink, $\Delta P_{h s}$, the Thermal Resistance, $\mathrm{R}_{t h}$, and the Nusselt Number, $\mathrm{Nu}_{D r}$.

Table 3: Values of parameters considered in Base Case

\begin{tabular}{|c|c|c|}
\hline \multicolumn{2}{|l|}{ Parameter } & Value \\
\hline \multicolumn{2}{|c|}{ Air Inlet Temp. $\left(\mathrm{C}^{0}\right)$} & 27 \\
\hline \multicolumn{2}{|c|}{ Heat Input( Watt) } & 30 \\
\hline \multicolumn{2}{|c|}{ Fluid Velocity $(\mathrm{m} / \mathrm{s})$} & 1 , and 5 \\
\hline \multirow{5}{*}{$\begin{array}{l}\text { Heat sink } \\
\text { Dimension }\end{array}$} & Fin Height $\mathrm{H}$ & $35 \mathrm{~mm}$ \\
\hline & Fin Thickness $t_{f}$ & $1.5 \mathrm{~mm}$ \\
\hline & Fin Number N & 12 \\
\hline & Length L & $100 \mathrm{~mm}$ \\
\hline & Width H & $100 \mathrm{~mm}$ \\
\hline \multicolumn{2}{|c|}{ Heat Shield angles $\theta$ ( degree) } & 90 \\
\hline
\end{tabular}

Fig. (10) shows the velocity, pressure, and temperature contours as well as the streamlines in section A-A for both cases (with and without shield). Also, pressure along the bottom wall of the test section is shown.

As shown in velocity contours for the bypass flow case, the flow accelerates as it enters the bypass region. Nearly, most of the mass flow rate passes through the bypass region and the remaining part of the flow that performs the forced convection passes through the fin-to-fin channels with generating a recirculation zone downstream the heat sink due to its blockage effect. When the shield is present, the blockage effect of a shield forces more coolant fluid to pass through the heat sink and increases the velocity in the fin-to-fin channels. So it is expected that the presence of the shield will bestow an advantage of enhancing the heat transfer from the heat sink. Moreover, recirculation zones occur in the flow field upstream and downstream the shield.

Also, the figure shows the pressure contours in section A-A and the pressure distribution along a line passing in the middle of the bottom wall of the test section. As shown, due to the blockage effect of the heat sink, the pressure evidently increases in front of a heat sink. As the fluid enters the heat sink, the pressure at the centerline of the heat sink decreases significantly. Just downstream the heat sink the pressure decreases significantly due to the formation of a recirculation zone.
The pressure recovers again after a distance nearly equal to $1.5 \mathrm{H}$ (Fin Height). Also, the presence of a shield causes a greatly increased pressure upstream of the heat sink in turn, increases the pressure drop across the heat sink.

Temperature contours that are shown in Fig. (10) show that heat transfer occurs first from the heating element to the heat sink base and fins by conduction and then to air passing over fins and base by convection. The temperature decreases from the bottom to the top and from the middle to the exterior. It is lower in the front than in the rear of the heat sink. The temperature of the flow in the bypass region is almost the same as the inlet temperature, which indicates that the bypass flow hasn't a considerable cooling effect. The flow that passes through the inter-fin spaces generates temperature gradient beside the hot solid surface and carries the generated heat downstream the heat sink.

The calculated behavior thermal resistance at different Reynolds numbers is shown in Fig. (11). In general, the thermal resistance decreases substantially and diminishes smoothly with increasing Reynolds number for both cases (without and with shield). Table (4) show that the decrease in thermal resistance due to the presence of thermal shield decreases as the Reynold's number increases from 23,600 to 55,000 . But the pressure drops across the heat sink increases dramatically due to the presence of heat shield as the Reynold's number increases as shown in Fig. (12). From the tabulated data it can deduce that it is recommended to use a heat shield at low Reynolds number since it makes nearly thermal resistance to decrease to its half value without too much increase in pressure drop and consequently the pumping power 
Bypass Flow Without shield

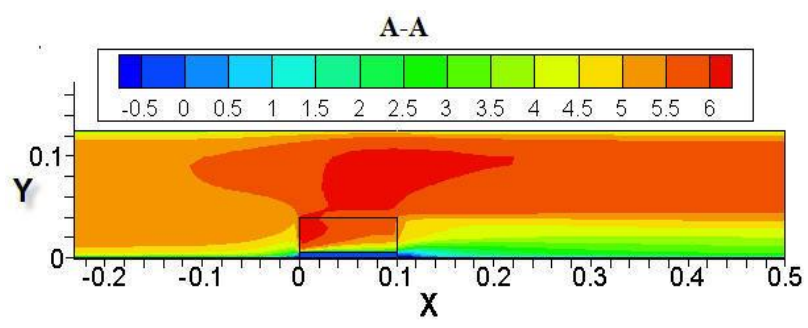

$\underline{\text { With shield }}$

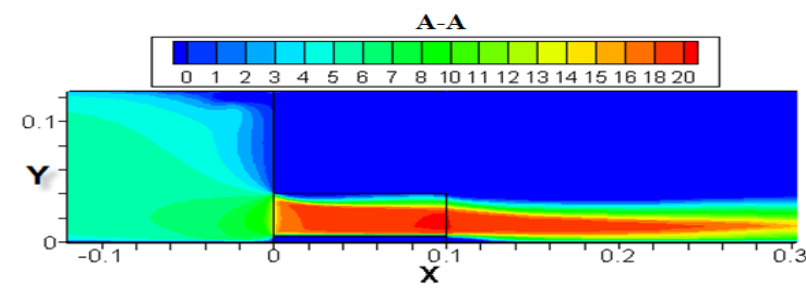

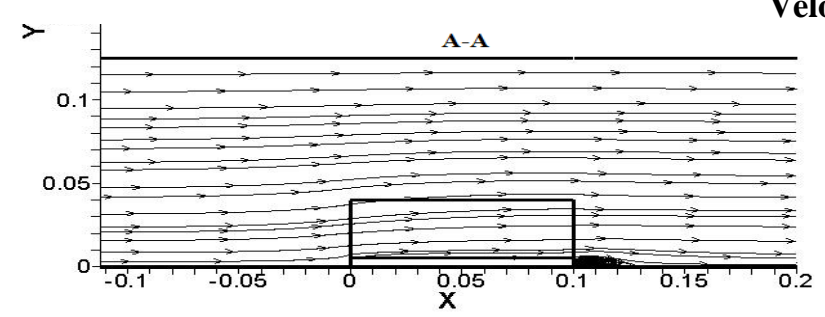

Velocity contours

A-A

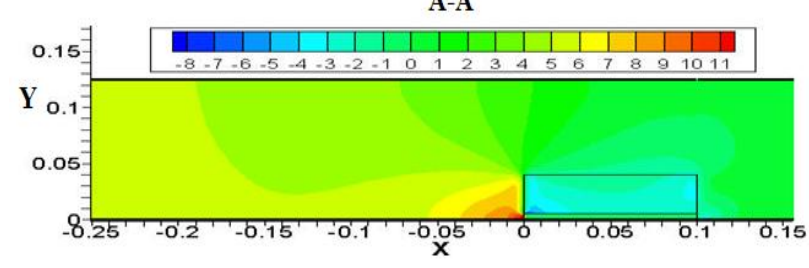

Pressure contours

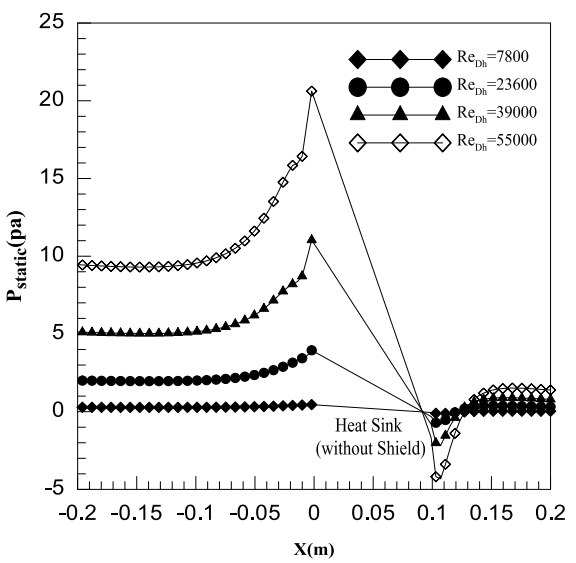

Flow pathlines

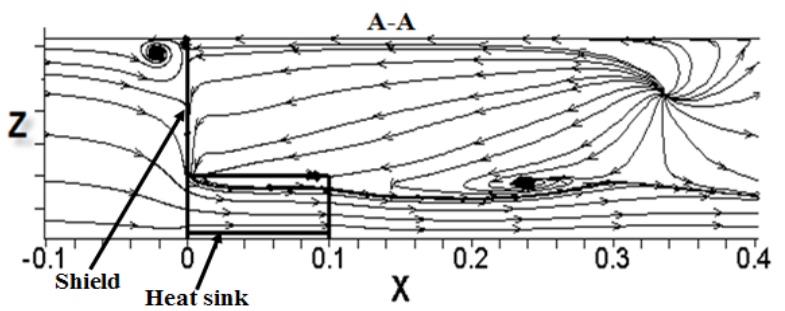

A-A
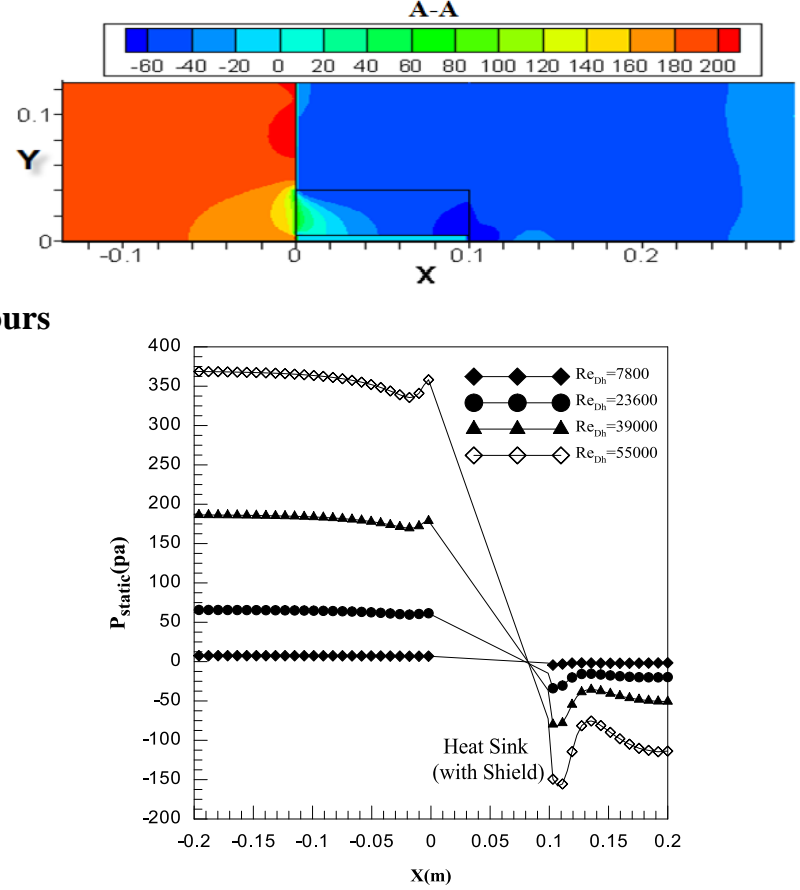

Pressure distribution along tunnel centerline
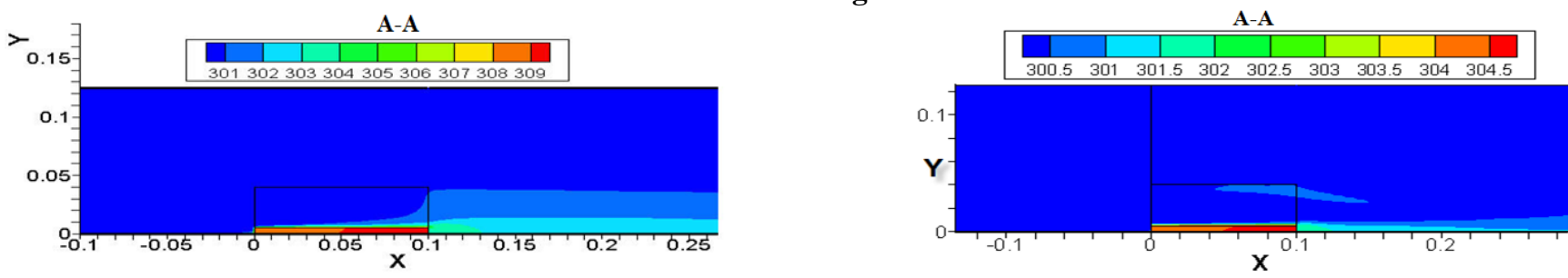

Temperature contours

Fig. (10) Effect of shield on some variables for base case heat sink

$$
\left(\operatorname{Re}_{\text {Dh}}=39,000\right)
$$




\section{Thermal Performance of Flat Plate Heat Sink With Attached Heat Shield}

Shaalan, Saleh, Mesalhy, Elsayed

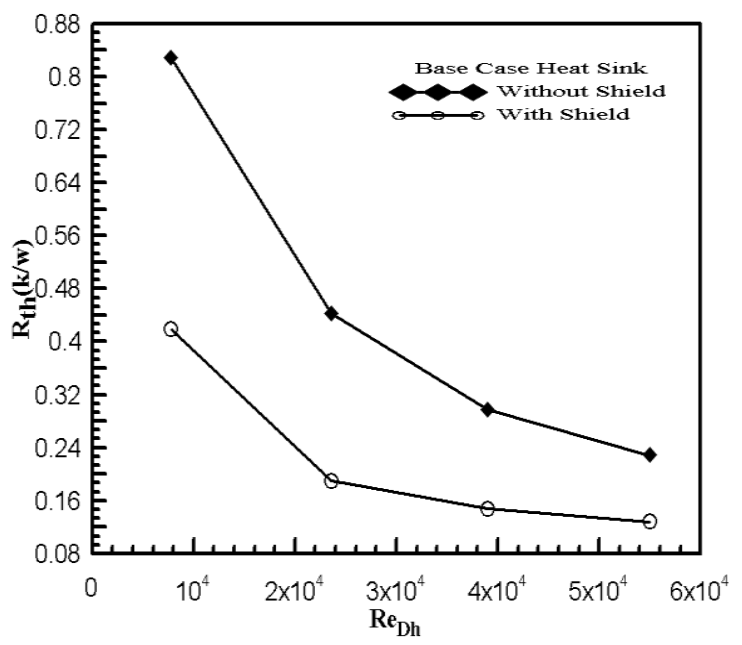

Fig.11: Effect of shield on thermal resistance of base case heat sink

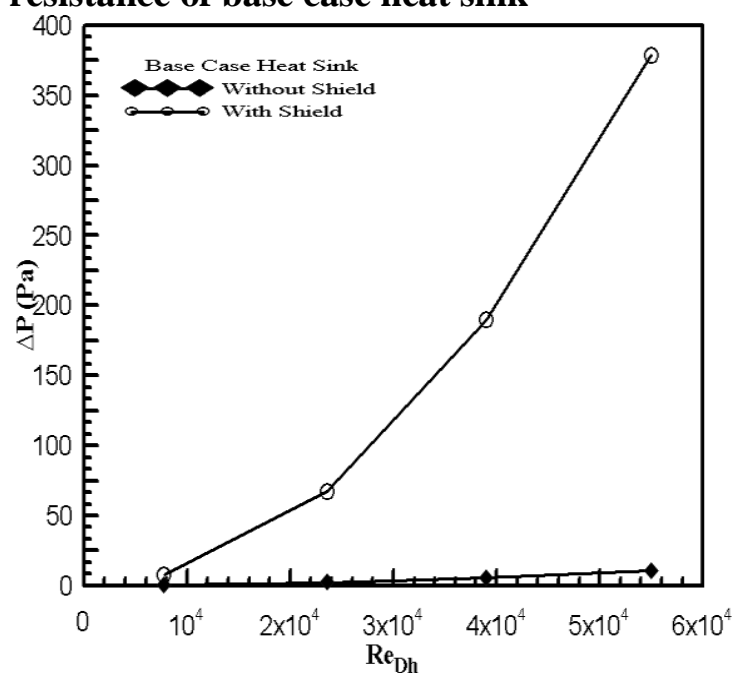

Fig. 12: Effect of shield on pressure drop across base case heat sink

Table 4: Change in thermal resistance and pressure drop due with shield

\begin{tabular}{|l|l|l|l|l|l|}
\hline $\mathrm{Re}_{\mathrm{Dh}}$ & Rth(wo) & Rth(w) & $\Delta \mathrm{p}(\mathrm{wo})$ & $\% \Delta \mathrm{p}$ increase & \%Rth decreases \\
\hline 7,800 & 0.828 & 0.418 & 0.32 & 7.69 & 49.5 \\
\hline 23,600 & 0.442 & 0.190 & 2.25 & 67.1 & 57 \\
\hline 39,000 & 0.297 & 0.148 & 5.7 & 189.7 & 50.1 \\
\hline 55,000 & 0.229 & 0.128 & 10.5 & 378.7 & 44.1 \\
\hline
\end{tabular}

Table 5: Values of test matrix parameters

\begin{tabular}{|l|l|l|l|}
\hline Parameter & Range studied & step & Base Case \\
\hline $\mathrm{Re}_{\mathrm{Dh}}$ & $7,800: 55,000$ & -- & -- \\
\hline Fin Height $\mathrm{H}$ & $15: 75 \mathrm{~mm}$ & $20 \mathrm{~mm}$ & $35 \mathrm{~mm}$ \\
\hline Fin Numbers N & $8: 28$ & 4 & 12 \\
\hline Shield Angle $\theta$ & $30^{\circ}: 150^{\circ}$ & $15^{\circ}$ & $90^{\circ}$ \\
\hline
\end{tabular}

\subsubsection{Effect of Reynolds number at different fin heights}

Fig. (13) Shows the effect of Reynolds number on the thermal performance of the heat sink, as expected, the thermal resistance decreases with increasing both Reynolds number and fin height. Increasing Reynolds number increases the cooling effect while increasing fin height increases the surface area. Installing a shield improves the thermal performance through reducing the heat sink thermal resistance especially for the case of lower Reynolds number and lower heat sink heights. As the heat sink height increases, the improving in thermal resistance due to installing shields slightly decreases. We can notice from the figure that the performance the heat sink of height equal to $75 \mathrm{~mm}$ with and without shield became closer to each other. It was found that shield inclination angle from $\theta=90-120^{\circ}$ is the optimum angle, which minimizes the thermal resistance of the heat sink.

\subsubsection{Effect of fin height}

Thermal resistance plotted versus heat sink heights for $\mathrm{N}=20$ at different Reynolds number as shown in Fig. (14). It shows the same trends of variation of thermal resistance with heat sink height and Reynolds number that are showed in Fig.(13). But the figure shows that with installing shield, increasing fin height more than $55 \mathrm{~mm}\left(\mathrm{H} / \mathrm{C}_{\mathrm{H}}=0.48\right)$ is not worthy in minimizing the thermal resistance.

\subsubsection{Effect of fin number}

Fig. (15) Shows the effect of fin numbers $(\mathrm{N}=8,12,16,20$ and 24$)$ of the plate-fin heat sinks, at various fin height with constant Reynolds number $\mathrm{Re}_{\mathrm{Dh}}=7,800$ on the thermal resistance of the heat sink with and without shield. It depicts the dependence of thermal resistance on the number of fins. The figure shows that the thermal resistance of the heat sink without shield decreases generally with increasing the number of fins. 
(a) $\mathbf{H}=15 \mathrm{~mm}$

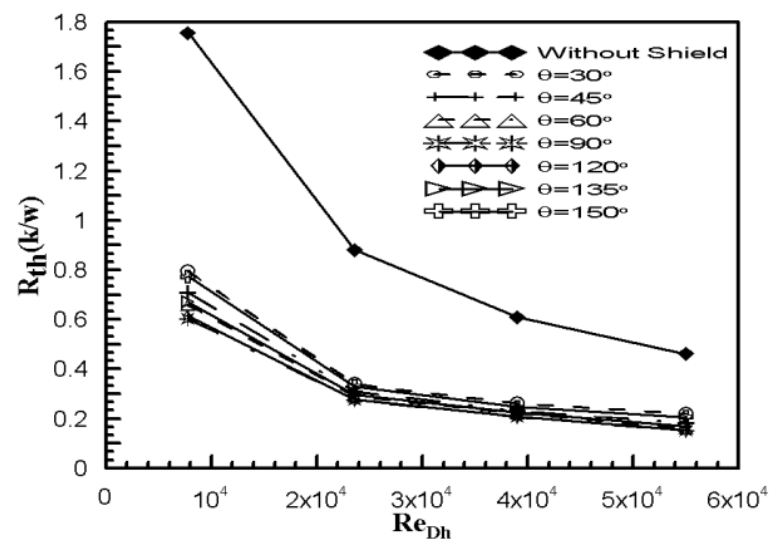

(c) $\mathbf{H}=55 \mathrm{~mm}$

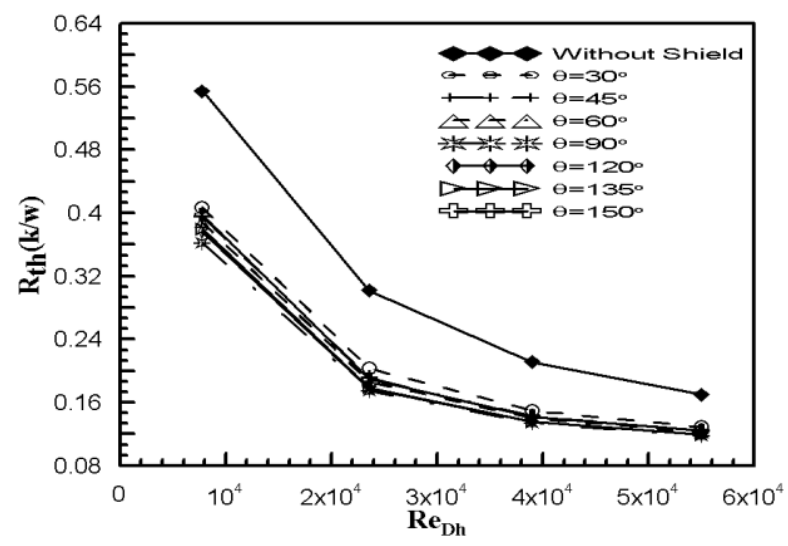

(b) $\mathbf{H}=\mathbf{3 5} \mathbf{~ m m}$

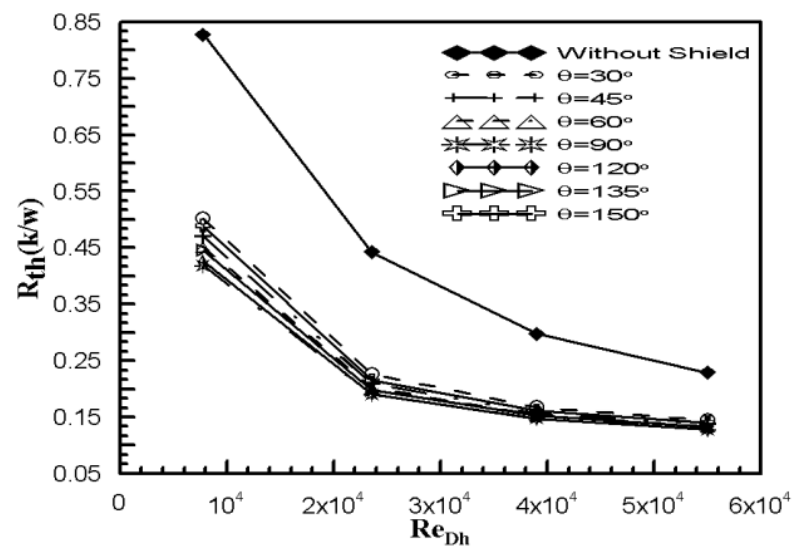

(d) $\mathrm{H}=75 \mathrm{~mm}$

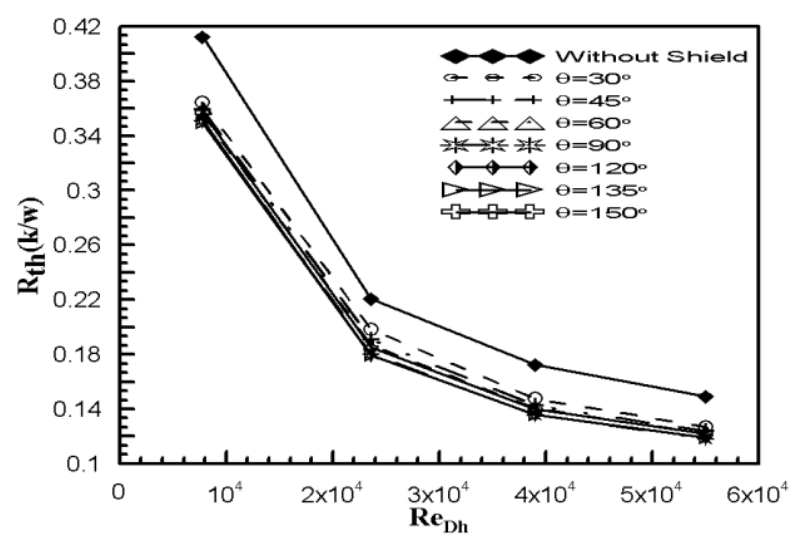

Fig. 13:Effect of Reynolds number on thermal resistance of heat sink (number of fins $N=12$ )

For $\mathrm{H}=15 \mathrm{~mm}$, the thermal resistance reached its minimum value at $\mathrm{N}=20$, which means that this number of fin is the optimum for a heat sink with $\mathrm{H}=15 \mathrm{~mm}$ and operating at $\mathrm{Re}$ $=7,800$. This optimum operating point occurs because of the two contradicting effects of increasing the fin number. These effects are increasing the heat transfer surface area and increasing the blockage effect. Using a heat sink with larger fin height or operating the heat sink at higher Reynolds number makes the heat sink to attain minimum thermal resistance at higher fin number. It is shown also from the figure that using the thermal shield eliminated this optimum point $(\mathrm{N}=20$ at $\mathrm{Re}=7800$ and $\mathrm{H}=15 \mathrm{~mm}$ ), which means that adding thermal shield makes it possible to increase the number of fins to gain more improvement in the thermal performance.

\subsubsection{Effect of inclination angle}

Fig.(16) show the behavior of the thermal resistance for a heat sink with fin number $\mathrm{N}=12$ and height $\mathrm{H}=15,35,55$ and $75 \mathrm{~mm}$ at various inclined angles of a plate shield and at various Reynolds numbers. [Fig.18a and b] shows thermal resistance versus $\theta$ for a heat sink at $\mathrm{H}=15$ and $35 \mathrm{~mm}$, respectively. The Figure shows also a comparison between the measured and the predicted values, which shows good agreement in both magnitude and the trend of the data. The results of thermal resistance emphasis on the higher effect of using thermal shield on thermal performance especially in the case of lower heat sink height and lower Reynolds number. It is found that the angle of inclination that yield minimum thermal resistance ranges from $90-120^{\circ}$ for lower heat sink height, while for higher heat sink height the optimum heat shield angle ranges between $120-135^{\circ}$. 
(a) $\mathrm{Re}=\mathbf{7 8 0 0}$

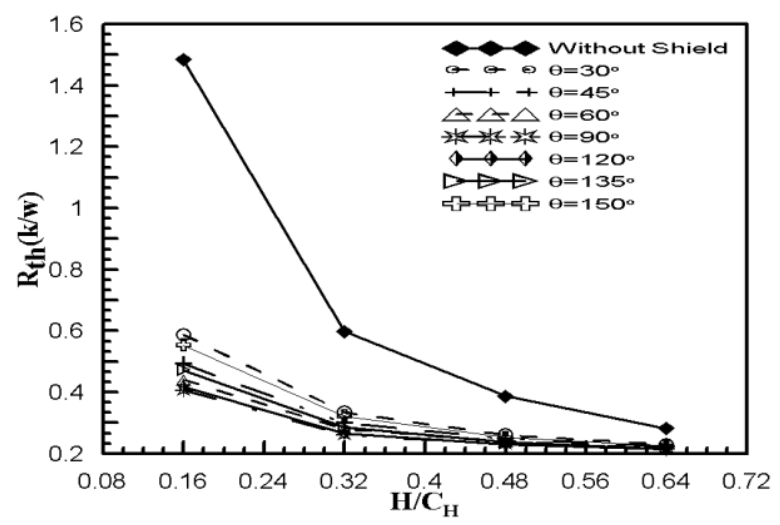

(c) $\operatorname{Re}=39000$

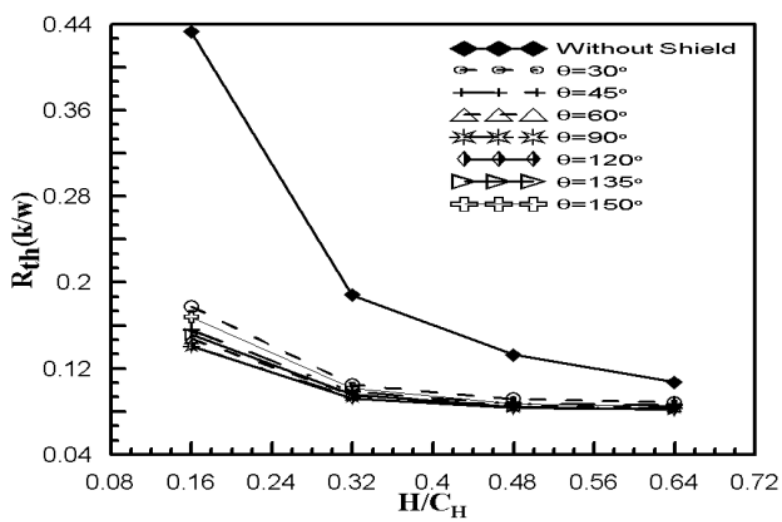

(b) $\mathrm{Re}=\mathbf{2 3 6 0 0}$

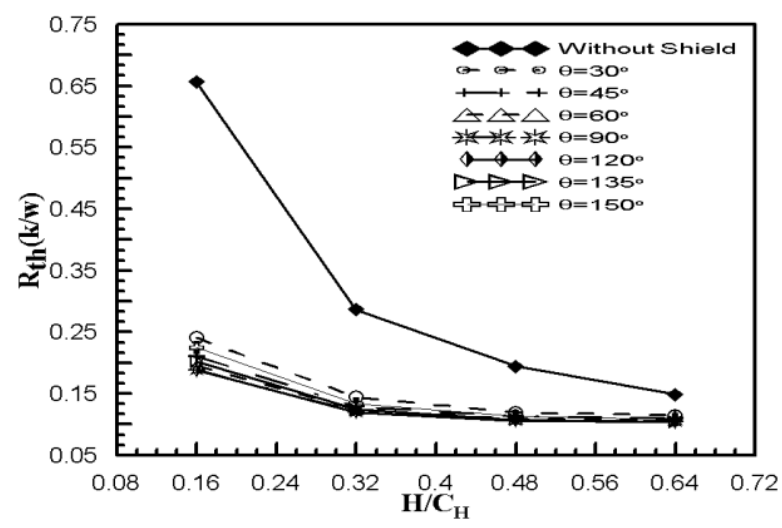

(d) $\operatorname{Re}=55000$

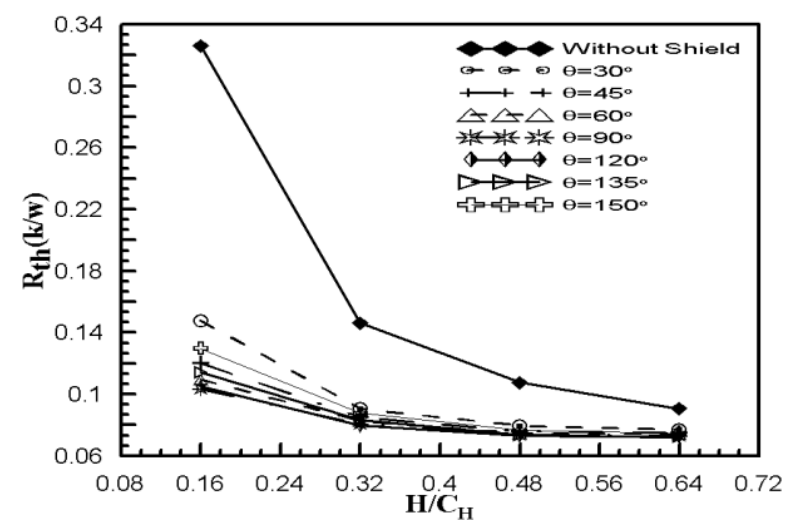

Fig. 14: Effect of fin height to channel height on thermal resistance of the heat sink (number of fins $N=20$ )

(a) $\mathrm{H}=15 \mathrm{~mm}$

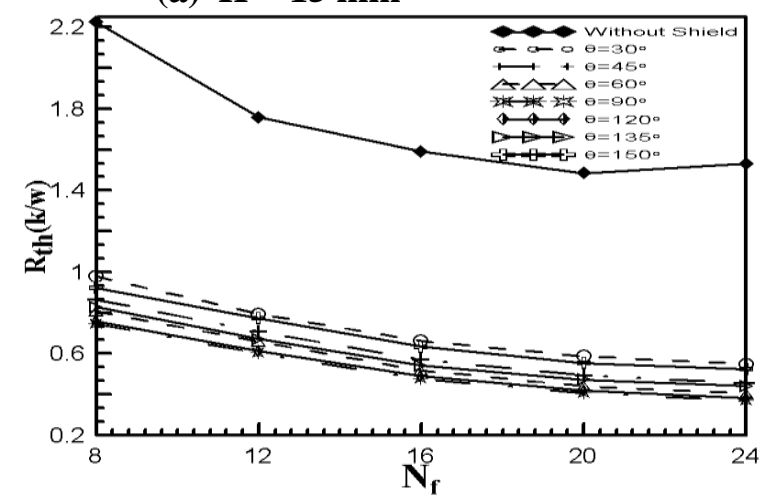

(c) $\mathrm{H}=55 \mathrm{~mm}$

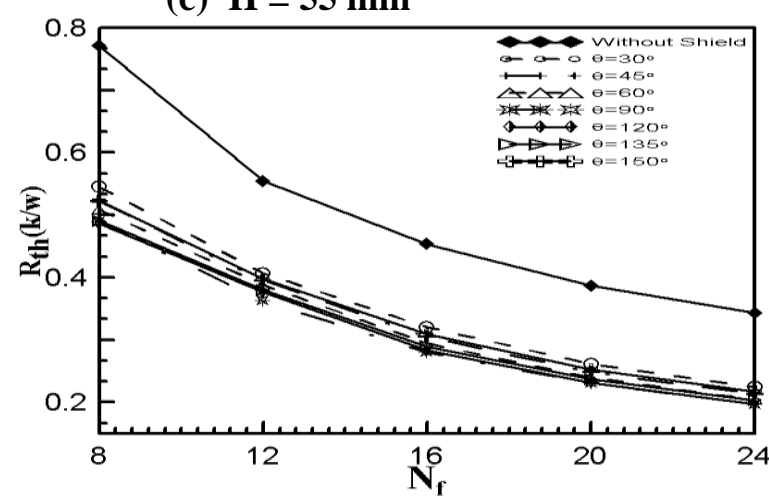

(b) $\mathbf{H}=\mathbf{3 5} \mathbf{~ m m}$

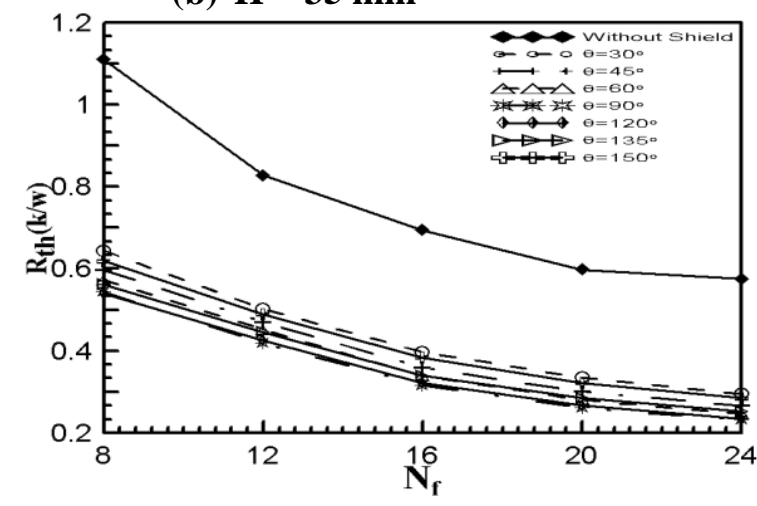

(d) $\mathbf{H}=\mathbf{7 5} \mathrm{mm}$

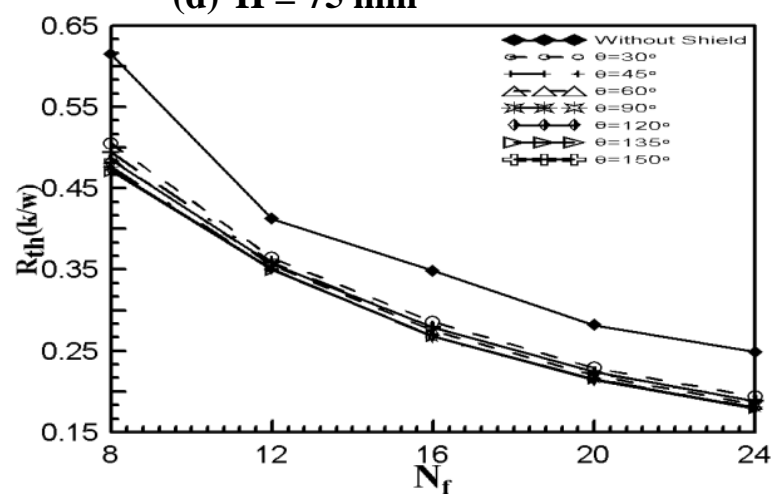

Fig.15: Effect of number of fins on thermal resistance of heat sink Reynolds number $\left(\operatorname{Re}_{\mathrm{Dh}}=\mathbf{7 8 0 0}\right)$ 
(a) $\mathrm{H}=15 \mathrm{~mm}$

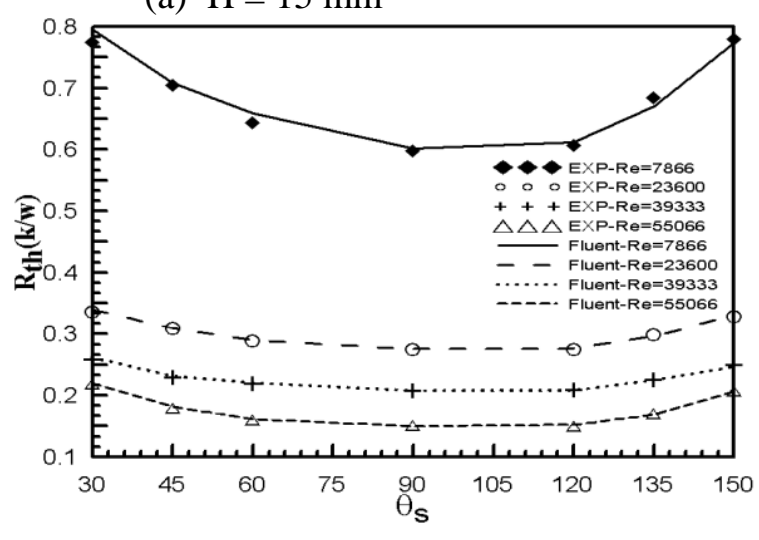

(c) $\mathrm{H}=55 \mathrm{~mm}$

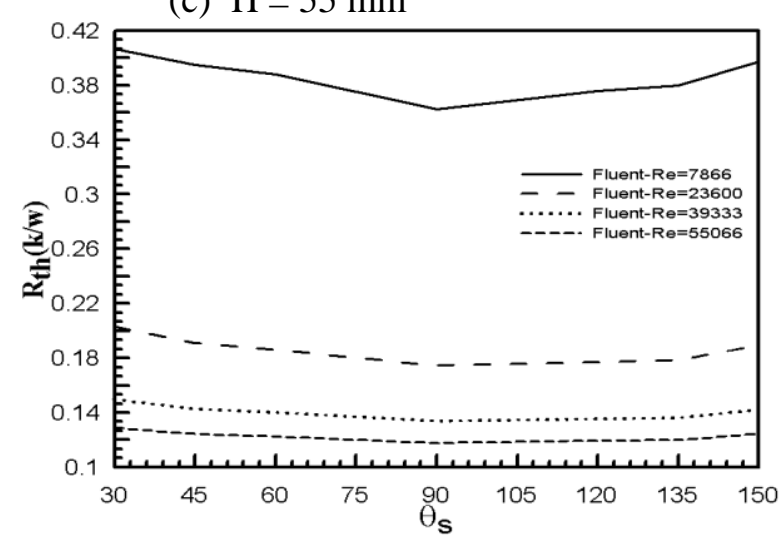

(b) $\mathrm{H}=35 \mathrm{~mm}$

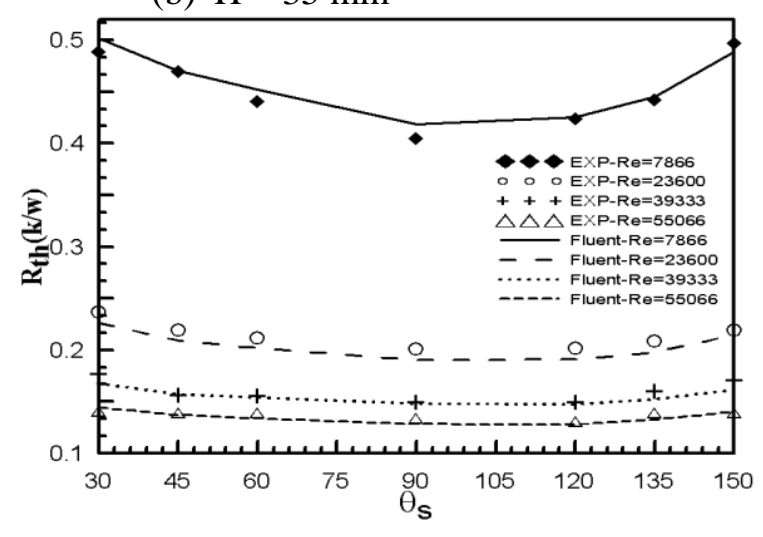

(d) $\mathrm{H}=75 \mathrm{~mm}$

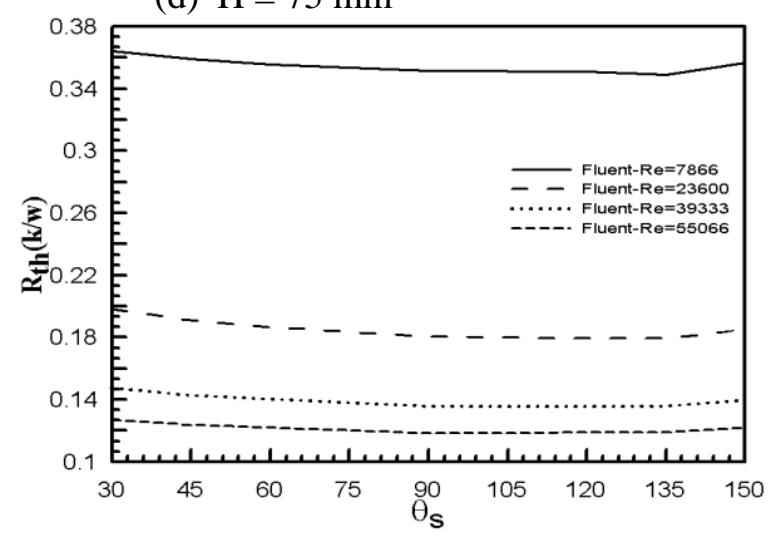

Fig.16: Effect of shield inclination angle on thermal resistance of heat sink (number of fins $N=12$ )

\section{CONCLUSIONS}

The thermal performance of plate-fin heat sinks undergoing cross-flow cooling has been studied experimentally and numerically both with and without a heat shield. Based on the results of this study and the analysis of the impact of the controlling parameters, the following conclusions are drawn.

* Thermal resistance decreases significantly with a decrease in fin spacing or increase in fin height for the same volumetric flow rate. Also, there exists optimum fin spacing or fin height for system operation.

* Thermal performance improves as the Reynolds number increases until a certain value, at which the improvement becomes limited.

* The attachment of a shield to a heat sink enhances the thermal performance and thermal resistance decreases with increasing Reynolds number, but this effect diminishes at high Reynolds numbers. The enhancement of thermal performance by a shield is much greater and effective at low Reynolds numbers.

* Increasing the fin height enhances the performance of the heat sink, but the effectiveness decreases with increasing Reynolds number. Increasing the fin height also decreases the height of a shield, in turn, decreasing the impact of blockage on thermal resistance.

* The optimal number of fins increases with increasing Reynolds number, and is greater with a shield at low Reynolds numbers. * $\quad$ For the case of the smallest fin height, $\mathrm{H}=15 \mathrm{~mm}$, it is found that the angle of inclination that yield minimum thermal resistance ranges from $90-120^{\circ}$, while for higher heat sink height the optimum heat shield angle ranges between $120-135^{\circ}$. 


\section{Thermal Performance of Flat Plate Heat Sink With Attached Heat Shield}

Shaalan, Saleh, Mesalhy, Elsayed

\section{REFERENCES}

[1]A.M. Morega, A. Bejan, S.W. Lee, Free stream cooling of a stack of parallel plates, Int. J. Heat Mass Transfer 38 (1995) 519-531.

[2]E. M. Sparrow, B. R. Baliga, and S. V. Patankar, "Forced convection heat transfer from a shrouded fin array with and without tip clearance," ASME J. Heat Transf., vol. 100, pp. 572-579, Nov. 1978.

[3]E. M. Sparrow and D. S. Kadle, "Effect of tipto-shroud clearance on turbulent heat transfer from a shrouded, longitudinal fin array," ASME J. Heat Transf., vol. 108, pp. 519-524, Aug. 1986.

[4] R.A. Writz, W. Chen, R. Zhou, Effect of flow bypass on the performance of longitudinal fin heat sinks, ASME J. Electron. Packag. 116 (1994) 206211.

[5]K. Azar, B. Tavassoli, How much heat can be extracted from a heat sink, Electronics Cooling, May 2003, pp. 1-9.

[6]R.E. Simons, Estimating the Effect of Flow Bypass on Parallel Plate- Fin Heat Sink Performance, ElectronicsCooling.com/html/2004,February-cc.html.

[7]E.A.M. Elshafei, Effect of flow bypass on the performance of a shrouded longitudinal fin array, Applied Thermal Engineering 27 (13) (2007) 2233-2242.

[8]H. Jonsson, B. Palm, Thermal and hydraulic behavior of fin and strip fin heat sinks under varying bypass conditions, IEEE Transactions on Components and Packaging Technologies 23 (1) (2000) 47-54.

[9]V.B. Adam, F.O. Izundu, Characterization of longitudinal fin heat sink-thermal performance and flow bypass effects through CFD method, SEMITHERM, Thermal and Fluid Flow Analysis Software, MAYA, 1997.
[10]T.D. Yuan, Computational modeling of flow bypass effects on a straight fin heat sink in a rectangular duct, Twelfth IEEE Semi-therm Symposium, 1996, pp. 164-168.

[11]S. Prstic, A. Bar-Cohen, Heat shield-an enhancement device for an unshrouded, forced convection heat sink, Journal of Electronic Packaging 128 (2) (2006) 172-176.

[12] H.Y. Li, G.L. Tsai, S.M. Chiang, J.Y. Lin, Effect of a shield on the hydraulic and thermal performance of a plate-fin heat sink, International Communications in Heat and Mass Transfer 36 (3) (2009) 233-240.

[13]Seaho S., Lee, S., Van A. and Kevin P. M., "Constriction/Spreading Resistance Model For Electronics Packaging," Asme/Jsme Thermal Engineering Conference: Volume 4, ASME 1995.

[14]FLUENT 6.3.26 User's Guide, 2006, FLUENT Inc. 